\title{
Glutamine deprivation-mediated cell shrinkage induces ligand-independent CD95 receptor signaling and apoptosis
}

\author{
C Fumarola ${ }^{1}$, A Zerbini ${ }^{1}$ and GG Guidotti ${ }^{\star, 1}$ \\ ${ }^{1}$ Department of Experimental Medicine, Section of Immunology and Molecular \\ Pathology, University of Parma, 43100 Parma, Italy \\ * Corresponding author: GG Guidotti, Department of Experimental Medicine, \\ Section of Immunology and Molecular Pathology, University of Parma, Via \\ Volturno 39, 43100 Parma, Italy. Tel: +39 0521 903761/2; Fax: +39 0521 \\ 903742; E-mail: guido.guidotti@unipr.it
}

Received 22.1.01; revised 27.4.01; accepted 2.5.01

Edited by T Cotter

\begin{abstract}
Cell shrinkage and loss of cell viability by apoptosis have been examined in cultured CD95(Fas/Apo-1)-expressing leukemiaderived CEM and HL-60 cells subjected to acute deprivation of glutamine, a major compatible osmolyte engaged in cell volume control. Glutamine deprivation-mediated cell shrinkage promoted a ligand-independent activation of the CD95mediated apoptotic pathway. Cell transfection with plasmids expressing FADD-DN or v-Flip viral proteins pointed to a functional clustering of CD95 receptors at the cell surface with activation of the 'extrinsic pathway' caspase cascade. Accordingly, cell shrinkage did not induce apoptosis in CD95 receptor-negative lymphoma L1210 cells. Replacement of glutamine with surrogate compatible osmolytes counteracted cell volume decrement and protected the CD95expressing cells from apoptosis. A glutamine deprivationdependent cell shrinkage with activation of the CD95mediated pathway was also observed when asparaginase was added to the medium. Asparagine depletion had no role in this process. The cell-size shrinkage-dependent apoptosis induced by glutamine restriction in CD95-expressing leukemic cells may therefore be of clinical relevance in amidohydrolase enzyme therapies. Cell Death and Differentiation (2001) 8, 1004-1013.
\end{abstract}

Keywords: cell-shrinkage; CD95 (Fas/Apo-1) receptor; apoptosis; glutamine; asparaginase

Abbreviations: ALL, acute lymphoblastic leukemia; CD95L, CD95 ligand; DISC, death-inducing signaling complex; FADD, Fasassociated death domain protein; FADD-DN, dominant negative FADD; GFP, green fluorescent protein; OMG, 3-o-methyl-Dglucose; TNFR, tumor necrosis factor receptor; z-DEVD, Asp-GluVal-Asp; z-IETD, Iso-Glu-Thr-Asp

\section{Introduction}

L-Glutamine, the most abundant free amino acid of the human body, has a central role in the energy metabolism of many tissues, ${ }^{1-5}$ is a growth-limiting amino acid for several cell types including lymphocytes ${ }^{6-9}$ and leukemia cell lines, ${ }^{10,11}$ engages in cell volume control as compatible osmolyte ${ }^{12,13}$ and serves as a precursor of neurotransmitters. ${ }^{14}$ Previous studies with cultured human leukemia/lymphoma cell lines (CEM, HL-60, U937, Namalwa) indicated that glutamine restriction induces loss of cell viability by apoptosis. ${ }^{15,16}$ When these cells encountered a medium-glutamine concentration lower than $0.3-0.4 \mathrm{mM}$ for at least $24 \mathrm{~h}$ ceased multiplying and entered the apoptotic pathway, unless glutamine was reinstated to values compatible with the resumption of proliferation. ${ }^{16}$ Lymphoblastic leukemia-derived $\mathrm{CEM} \mathrm{CD} 4^{+}$-enriched cells, clone 13 , used in the present study, express the MYC oncoprotein ${ }^{17}$ and are highly susceptible to agonistic anti-CD95 antibody-induced apoptosis (C Fumarola and GG Guidotti, unpublished observations), a death pathway sensitized by c-myc overexpression. ${ }^{18,19}$ CD95 (Fas/Apo-1) is a death-promoting receptor that belongs to the tumor necrosis factor receptor (TNFR) family. Surface clustering of CD95 induced by natural ligands (CD95L) or by agonistic antibodies is required for the transduction of the apoptotic signal. ${ }^{20,21}$ The death pathway involves oligomerization of the initiator caspase-8 and its proximity-induced autoproteolytic activation via recruitment of adapter FADD molecules in a death-inducing signaling complex. ${ }^{22}$ Active caspase-8 cleaves a number of proteins including procaspase-3, which results in its activation with completion of the cell death program in type I cells, ${ }^{23}$ and Bid, ${ }^{24,25}$ a Bcl-2 family member that leads to amplification of the caspase cascade in type II cells. ${ }^{23}$ Assembly of CD95 receptors with activation of the apoptotic pathway independently of CD95 ligand-receptor interaction has been induced in several mammalian cell types by ultraviolet (UV) light exposure, ${ }^{26,27}$ in murine hepatocytes by toxic bile salts ${ }^{28}$ and in colon carcinoma cells by some anticancer drugs. ${ }^{29}$ In H1299 (p53-null) lung carcinoma cells, UV irradiation has been shown to promote apoptosis by ligand independent aggregation of TNFR-1. ${ }^{30}$

Here we report that in cultured CEM cells clone 13 , and in other cells (CEM-CCRF and HL-60) expressing a functional CD95-dependent signaling mechanism, cell shrinkage associated with glutamine deprivation promotes a ligand-independent activation of surface CD95 receptors. Cell shrinkage presumably arises from the decrement of intracellular osmolytes and release of osmotically obliged water. The surface receptor assembly launches the extrinsic death pathway by recruitment of FADD adapter molecules and caspase-8 autoproteolytic activation. A comparable induction of the CD95-dependent caspase 
cascade that triggers apoptosis is also observed when glutamine concentration in the medium of cultured CEM and HL-60 cells is lowered to exhaustion by adding $E$. coli asparaginase (L-asparagine amidohydrolase), an enzyme preparation that has glutaminase activity. Activation of apoptotic pathways seems to be fundamental in chemotherapeutic strategies whereby anti-oncogenic agents effect their responses. In the combined therapy of childhood acute lymphoblastic leukemia (ALL) the administration of amidohydrolase enzymes as asparaginase or glutaminaseasparaginase from bacterial sources ${ }^{31-35}$ is associated with a marked reduction of glutamine concentration in body fluids. $^{36-38}$ The cell-size shrinkage-dependent apoptosis induced by glutamine depletion in CD95-expressing leukemic cells may therefore be relevant to the antineoplastic activity and to the sites of toxicity in the therapy with amidohydrolase enzymes.

\section{Results \\ Glutamine deprivation activates the CD95 signaling pathway and promotes apoptosis}

The treatment of CEM cells with an agonistic IgM anti-CD95 antibody $(\mathrm{CH}-11)$ resulted in a massive apoptosis. As monitored by DNA fragmentation, apoptosis was prevented by specific inhibitors of caspase-8 (z-IETD) and caspase-3 (zDEVD) (Figure 1a), to indicate that these cells possess a functional CD95 signaling mechanism. When incubated in a glutamine-free medium, CEM cells entered an apoptotic pathway as shown by rapid activation of caspase-8 and caspase-3 (Figure 1b), DNA fragmentation (Figure 1c) and morphology (Figure 1d). In the early intervals (up to $6 \mathrm{~h}$ of incubation) Annexin V-FITC-positive cells excluded propidium iodide. DNA fragmentation was completely prevented by inhibitors of caspase- 8 and caspase- 3 and similar results were obtained in the CD95-expressing HL-60 and CEMCCRF cells (Figure 1e). These results suggest that the apoptotic death promoted by glutamine deprivation is associated with the induction of the CD95-dependent caspase cascade. In all cell models used, glutamine deprivation-dependent caspase activation and cell death were asynchronous, but consistent events. Under the same conditions, glutamine deprivation did not induce apoptosis in CD95-negative murine lymphoma L1210 cells (see Figure 5).

\section{Glutamine deprivation induces apoptosis independently of CD95L-CD95 interaction}

Total expression of CD95 in CEM cells, as quantitated by photometric immunoassay, was not affected by a 24-h glutamine deprivation (not shown) and, within this period of time, cytofluorimetric analysis showed that this treatment did not change its surface expression (Figure 2a). The treatment of CEM cells with neutralizing anti-CD95L (NOK-1) and antiCD95 (SM1/23) antibodies that block CD95L-mediated apoptosis failed to protect them from glutamine deprivationinduced cell death (Figure 2c,d). Western blot analysis (using two different primary anti-CD95L antibodies, $\mathrm{N}-20$ and clone 33) showed that the CD95 ligand protein was expressed in
CEM cells but, as shown in Figure $2 b$, its level was not affected by glutamine deprivation. Flow cytometry of CEM cells stained for CD95L indicated that the ligand was not on the cell surface and that glutamine deprivation did not promote its surface delivery from intracellular stores. However, on reaching the surface, the extracellular domain of CD95L is likely to be cleaved by a metalloproteinase ${ }^{39}$ producing a soluble form and a membrane-bound fragment that might be re-internalized. Experiments were therefore performed in the presence of a metalloproteinase inhibitor, but again flow cytometry did not detect CD95L on the surface of cells incubated in the presence or absence of glutamine. To further exclude that a rapid recycling of CD95L may elude cytofluorimetric detection, while retaining agonistic activity, CEM cells were incubated in glutamine-containing or glutamine-free media supplemented with the metalloproteinase inhibitor and apoptosis was assessed by DNA fragmentation and cell morphology. In these experiments the inhibition of metalloproteinase was not associated with induction of apoptosis in control cells or with enhancement of it in cells incubated in the absence of glutamine (Figure 2e). In separate experiments performed in the absence of the metalloproteinase inhibitor, soluble CD95L was undetectable in media of CEM cells incubated in the presence or absence of glutamine. Taken together, these results argue against a role of CD95L-CD95 interaction in the glutamine deprivationinduced apoptotic cell death.

\section{Glutamine deprivation is associated with cell shrinkage and surface contraction}

Cell volume decreased rapidly when CEM cells were transferred from a glutamine-containing into a glutamine-free RPMI 1640 (supplemented with glutamine-free FCS). This cell shrinkage presumably followed the significant decrement of intracellular osmolytes, as indicated by a lowered glutamine/ glutamate and NPS (ninhydrin positive substances ${ }^{40}$ ) cell content (results not shown), coupled with a release of osmotically obliged water. As estimated by measurements of cell water content based on transmembrane distribution of labelled 3-o-methyl- $D$-glucose (OMG), the mean cell volume decreased of approximately $15 \%$ within 60 min of incubation and shrinkage increased progressively up to $12 \mathrm{~h}$ when cell volume reached about $60 \%$ of its initial value (Figure 3a). Measurements of cell geometry parameters (area and diameter) by computer-assisted image analysis (see Materials and Methods) allowed to estimate the average cell surface contraction induced by glutamine deprivation (13\% of the initial value after $6 \mathrm{~h}$ of incubation) and to extrapolate a cell volume decrease close to $20 \%$ that confirmed the CEM cells shrinkage detected by OMG distribution. The glutamine deprivationinduced decrements in cell volume are greater when estimated from OMG distribution that measures water content (about $80 \%$ of the cell mass in our CEM clone) than when extrapolated from surface image measurements that apply to the entire cell mass. Afer proper correction for the quantity being measured, this discrepancy attenuates, suggesting that glutamine deprivation does not significantly affect the macromolecular mass of the cell. These results indicate that glutamine deprivation is followed by a loss of intracellular 
a

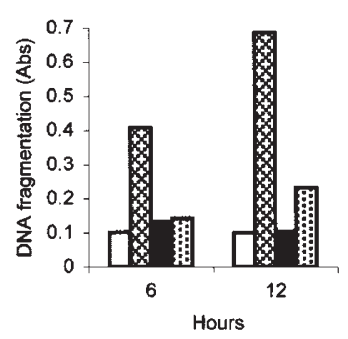

$d$

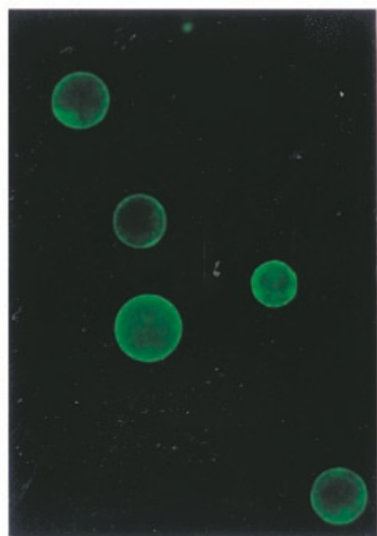

b

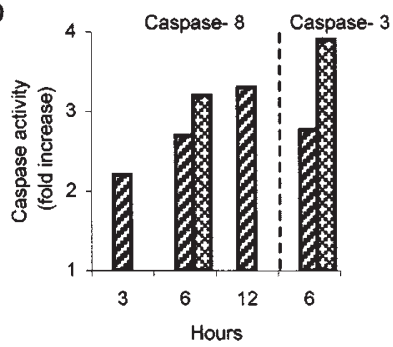

c

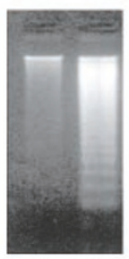

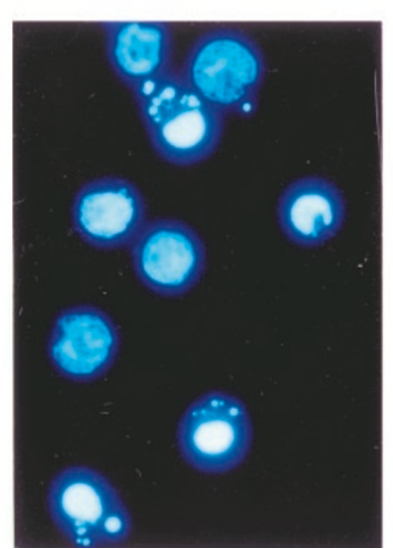

e

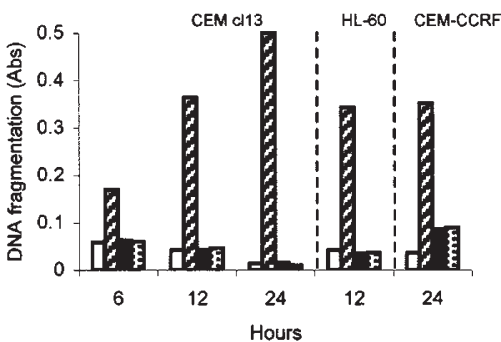

Figure 1 Apoptosis induced by anti-CD95 antibodies and by glutamine deprivation is prevented by caspase-8 and caspase-3 inhibitors. Cells (CEM clone 13, ad) CEM clone 13, CEM-CCRF and HL-60 cells, e) were incubated in $2 \mathrm{mM}$ glutamine-containing (controls) or in glutamine-free RPMl 1640 supplemented with $10 \%$ dialyzed FCS. (a) DNA fragmentation (photometric enzyme immunoassay) in control cells ( $\square$ ) and in control cells treated with $\mathrm{CH}-11$ anti-CD95 antibody (0.5 $\mu \mathrm{g} /$

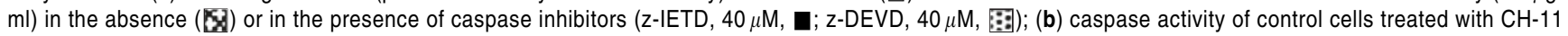
anti-CD95 antibody $(0.5 \mu \mathrm{g} / \mathrm{ml}$, or incubated in glutamine-free medium ( $)$ ); data are expressed as fold activation relative to control cells; (c) DNA laddering; low molecular-mass DNA extracted from control cells (left) or from cells incubated for $24 \mathrm{~h}$ in glutamine-free medium (right), and resolved in agarose gel electrophoresis; (d) morphology (fluoresence microscopy); cells incubated in glutamine-free medium for $6 \mathrm{~h}$ and stained with Annexin V-FITC (left) or for $24 \mathrm{~h}$ and stained with Hoechst 33342 (right). (e) DNA fragmentation (photometric enzyme immunoassay) in control cells ( $\square$ ) and in cells incubated in glutamine-free medium in the absence $(\boldsymbol{E})$ and in the presence of z-IETD $(40 \mu \mathrm{M}, \mathbf{D})$ or z-DEVD $(40 \mu \mathrm{M}$, 圆). Data in $\mathbf{a}, \mathbf{b}$ and $\mathbf{e}$ are from a representative experiment. Each experiment, repeated at least four times, yielded similar results

water that, in turn, accounts for the decrease in cell volume and for cell surface contraction. Comparable decrements in cell size (OMG) distribution were also observed in HL-60 (26\%), CCRF-CEM (18\%) and L1210 cells (38\%) incubated for $6 \mathrm{~h}$ in glutamine-free FCS-supplemented RPMI 1640.

\section{Cell shrinkage induces the CD95-dependent apoptotic pathway}

Cell shrinkage induced by glutamine deprivation was not prevented in CEM cells treated with the caspase-8 inhibitor ZIETD at concentrations that abolished apoptosis (Figure 3b,c), indicating that the cell volume decreased independently of caspase- 8 activation. In these experiments cell shrinkage preceded the activation of caspase-8 (barely detectable before $2-3 \mathrm{~h}$ of incubation) and the fragmentation of DNA (not shown). A cell shrinkage occurring upstream of caspase8 activation has been also induced in CEM cells by hyperosmotic stress (Fumarola, La Monica and Guidotti, unpublished results) and recently reported for Jurkat $T$ cells treated with agonistic anti-CD95 antibodies. ${ }^{41}$ The replacement of L-glutamine in the culture medium with $10 \mathrm{mM}$ betaine, a surrogate compatible organic osmolyte, ${ }^{12}$ fully counteracted the cell volume decrement at $3 \mathrm{~h}$ and allowed
CEM cells to retain more than $85 \%$ of their initial volume at $6 \mathrm{~h}$ (Figure 4a). Under these conditions the cells were significantly protected from apoptosis (Figure $4 b, c)$. Similarly, a remarkable inhibition of cell shrinkage and a comparable protection from apoptosis were obtained when L-glutamine was replaced by $6 \mathrm{mM}$ D-glutamine or by $5 \mathrm{mM}$ 2-methylaminoisobutyric acid, a nonmetabolizable amino acid analog ${ }^{42}$ (not shown). These results imply that the cell volume decrement drives the activation of the CD95-signaling death pathway. However, an apoptotic volume decrease (AVD) associated with the progression of apoptosis and promoted by the activation of $\mathrm{K}^{+}$and $\mathrm{Cl}^{-}$channels ${ }^{41,43-45}$ cannot be excluded. When all the amino acids were withdrawn from the culture medium a marked decrement in the cell volume ensued that was associated with caspase-8 activation and DNA fragmentation, whereas the presence of glutamine $(2 \mathrm{mM})$ in the medium deprived of all other amino acids prevented cell shrinkage, caspase-8 activation and DNA fragmentation (Figure $4 d-f$ ), and let CEM cells to retain viability for at least $20 \mathrm{~h}$. As reported above, glutamine deprivation caused a marked decrement in cell size also in mouse lymphoma L1210 cells (Figure 5a). However, in these CD95-negative cells the volume decrement was not followed by caspase-8 activation or DNA fragmentation (Figure $5 b, c$ ), 


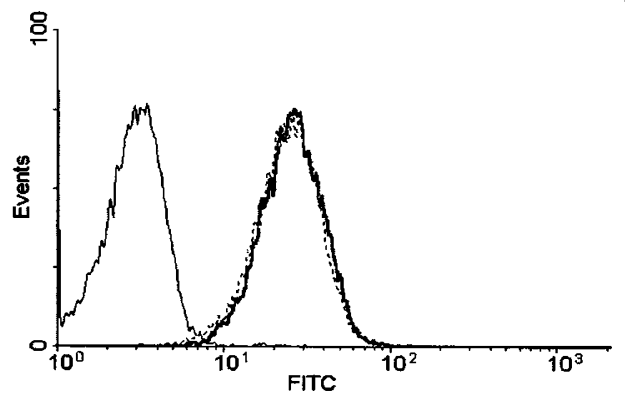

c

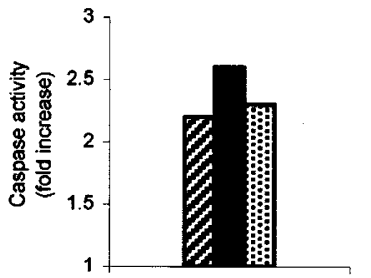

$d$

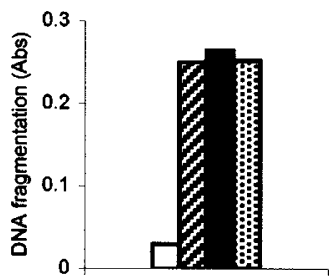

$b$

C
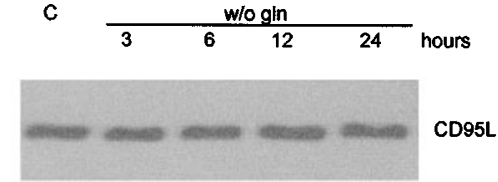

e

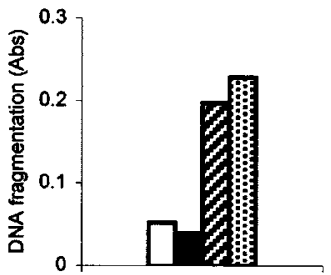

Figure 2 Apoptosis induced by glutamine deprivation is independent of CD95 ligand/CD95 interaction. CEM cells were incubated in glutamine-containing or in glutamine-free medium. (a) Surface expression of CD95 was determined by flow cytometry with the FITC-conjugated SM1/23 anti-CD95 antibody: left, isotypematched control antibody; right, positive monoclonal antibody in cells incubated for $6 \mathrm{~h}$ in the presence (continuous line) and absence of glutamine (dashed line);

(b) total expression of CD95L was estimated by Western blotting (using clone 33 monoclonal mouse anti-CD95L antibody) at the indicated time intervals; (c) caspase-8 activity (fold activation relative to control cells) and (d) DNA fragmentation (photometric enzyme immunoassay) were determined in cells incubated for $6 \mathrm{~h}$ in glutamine-containing $(\square)$ and in glutamine-free medium in the absence $(\mathbb{)})$ and in the presence of neutralizing anti-CD95 SM1/23 antibody $(10 \mu \mathrm{g} / \mathrm{ml}, \mathbf{})$ or anti-CD95L NOK-1 antibody (10 $\mu \mathrm{g} / \mathrm{ml}$, 目); (e) CEM cells were incubated in glutamine-containing (controls, $\square$ ) or in glutamine-free medium (deprived cells, $\mathbb{C}$ ) with KB8301 metalloproteinase inhibitor $(10 \mu \mathrm{M})$ added to control ( $\mathbf{\square})$ and deprived cells (圆). Data in a-e are from a representative experiment. Each experiment, repeated at least three times, yielded similar results

a

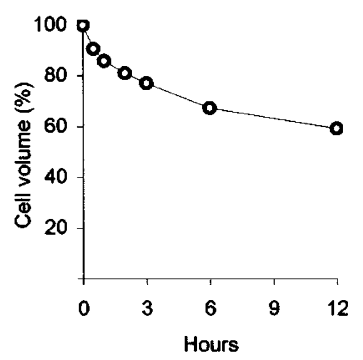

$b$

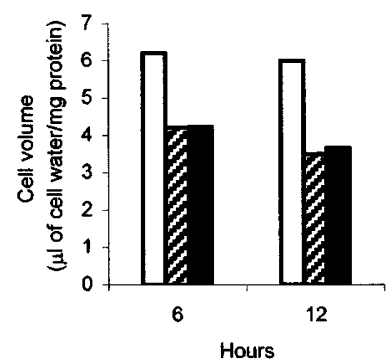

C

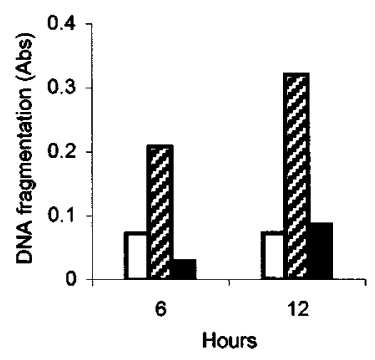

Figure 3 Glutamine deprivation promotes cell shrinkage upstream of caspase-8 activation. (a) CEM cells were incubated in glutamine-containing (controls) or in glutamine-free RPMI supplemented with $10 \%$ dialyzed FCS and cell volume was estimated at the indicated time intervals by measurements of the steady-state distribution of 3-0-methyl-D-[1- $\left.{ }^{3} \mathrm{H}\right]$ glucose $\left({ }^{3} \mathrm{H}-\mathrm{OMG}\right)$ added $30-40 \mathrm{~min}$ before the assay; data, expressed as per cent of the control value, are means of experiments. CEM cells were incubated in glutamine containing ( $\square$ ) or in glutamine-free medium in the absence ( $\mathbf{B})$ and in the presence of $40 \mu \mathrm{M}$ z-IETD ( $\mathbf{\square}):(\mathbf{b})$ cell volume estimated by transmembrane ${ }^{3} \mathrm{H}-\mathrm{OMG}$ distribution and expressed as $\mu$ of cell water/mg protein, and (c) DNA fragmentation determined by photometric enzyme immunoassay. Data in $\mathbf{b}$ and $\mathbf{c}$ are from a representative experiment. Each experiment, repeated at least three times, yielded similar results

suggesting that a functional membrane receptor-implemented death pathway was involved in the induction of the shrinkagedependent apoptosis in CD95-bearing cells.

\section{Cell shrinkage induces functional clustering of CD95 at the cell membrane}

In type II CEM cells the formation of the death-inducing signaling complex (DISC) is strongly reduced, but also in these cells FADD and caspase-8 seem to initiate the death signal at the CD95 receptor level ${ }^{23}$ (with mitochondria as subsequent amplifiers ${ }^{21}$ ). Figure $6 a, b$ show the cell shrinkage-induced activation of caspase-8 (cleavage products in Western blotting) and the inhibition of apoptosis in CEM cells transfected with a dominant negative form of FADD. ${ }^{46}$ To rule out that the apoptotic pathway promoted by CD95 receptor clustering at the cell surface was reinforced (or superseded) by a direct downstream oligomerization and autoactivation of caspase-8, CEM cells were cotransfected with the pEGFP-C1 vector along with plasmids expressing the $\mathrm{v}$-Flip viral proteins 
MC159 or $E 8^{47,48}$ and incubated in the presence and absence of glutamine. The expression of protein MC159 that binds to FADD $^{48}$ and disrupts normal formation of the death-inducing signaling complex inhibited the glutamine deprivation-induced apoptosis (Figure 6c), implying that a direct autoactivation of caspase- 8 does not take place and confirming that the cell shrinkage-dependent activation of the apoptotic pathway starts upstream. The expression of protein E8 that binds to the caspase- 8 prodomain ${ }^{48}$ and hinders its recruitment to the adaptor FADD also inhibited glutamine deprivation-induced apoptosis almost completely (Figure 6c), implying that an initial caspase-8 transactivation at the receptor level is required to propagate the caspase cascade. In CEM cells incubated in a glutamine-containing medium, the treatment with IgG divalent anti-CD95 antibodies (SM1/1, APO-1-3) did not affect the rate of proliferation for at least $24 \mathrm{~h}$ (Figure $6 \mathrm{~d}$ ) and was not accompanied by a detectable apoptotic effect (Figure 6e). In contrast, when CEM cells were incubated in the absence of glutamine, the treatment with divalent anti-CD95 antibodies suppressed proliferation, decreased cell viability (Figure 6d) and enhanced the apoptotic activity associated with glutamine deprivation toward levels observed in cells treated with agonistic IgM multivalent anti-CD95 antibodies (Figure 6f). These results suggest that the cell shrinkage promoted by glutamine deprivation increases close proximity of CD95 receptors (or receptor oligomers) to a membrane a

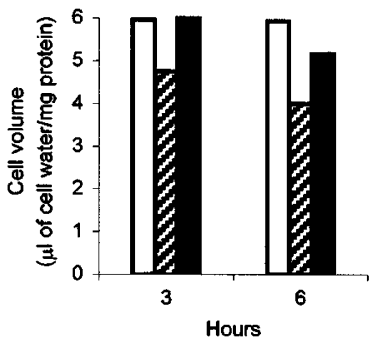

$d$

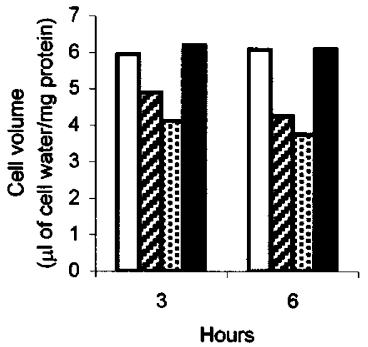

$b$

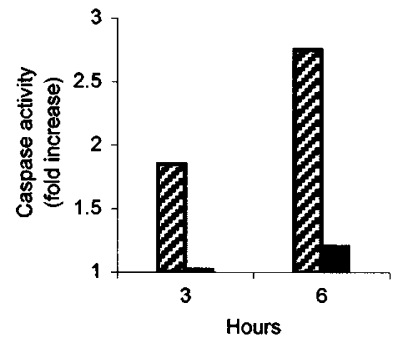

e

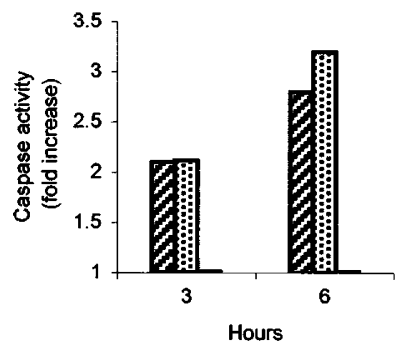

C

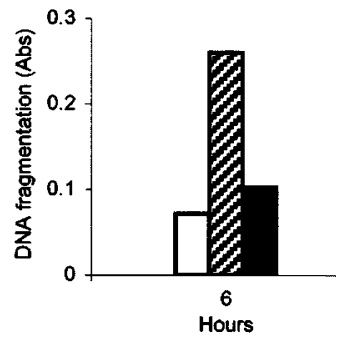

$f$

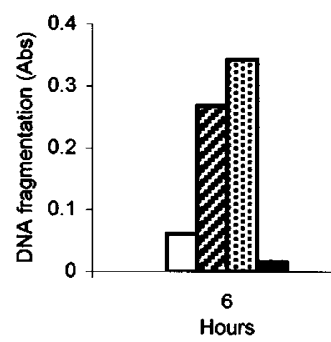

Figure 4 Glutamine deprivation-induced cell shrinkage and activation of the CD95-dependent pathway are restrained by surrogate compatible osmolytes. Glutamine supplementation prevents cell shrinkage and caspase-8 activation promoted by amino acid withdrawal. CEM cells were incubated for $3-6 \mathrm{~h}$ in glutamine-containing $(\square)$ or in glutamine free medium in the absence $(\mathbb{F})$ and in the presence of $10 \mathrm{mM}$ betaine $(\boldsymbol{\square})$; (a) cell volume ( $\mu$ l of cell water/mg protein), estimated by transmembrane ${ }^{3} \mathrm{H}-\mathrm{OMG}$ distribution; (b) caspase activity, expressed as fold activation relative to control cells and (c) DNA fragmentation, determined by photometric enzyme immunoassay. CEM cells were incubated in reconstituted complete- $(\square)$, glutamine-free- ( $\mathbb{B}$ ) or amino acid-free-RPMl in the absence ( $\mathbf{B}:$ ) and in the presence of $2 \mathrm{mM}$ glutamine ( $\mathbf{D}$ ); (d) cell volume ( $\mu \mathrm{l}$ of cell water/mg protein), estimated by transmembrane ${ }^{3} \mathrm{H}-\mathrm{OMG}$ distribution; (e) caspase activity, expressed as fold activation relative to control cells; (f) DNA fragmentation, determined by photometric enzyme immunoassay. Data in a-f are from a representative experiment. Each experiment, repeated at least three times, yielded similar results

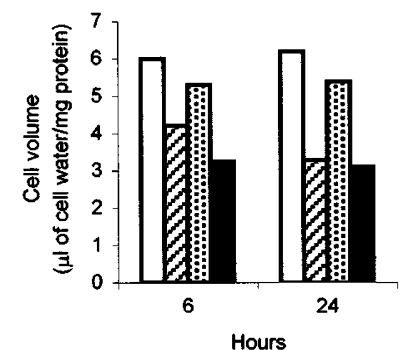

$b$

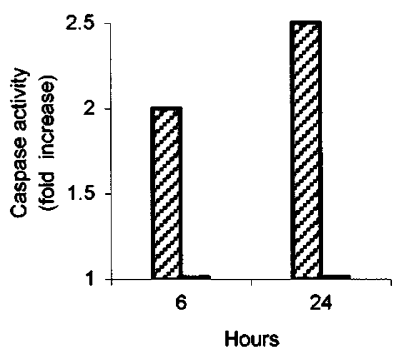

C

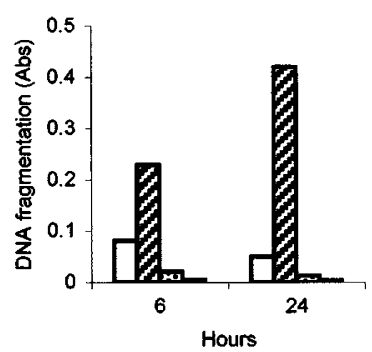

Figure 5 Glutamine deprivation-induced cell shrinkage fails to promote apoptosis in CD95-negative cells. Murine CD95-negative L1210 cells and CD95-

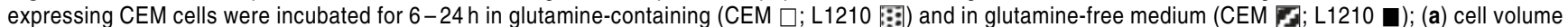
( $\mu$ l of cell water/mg protein), estimated by transmembrane ${ }^{3} \mathrm{H}-\mathrm{OMG}$ distribution; (b) caspase activity, expressed as fold activation relative to control cells and (c) DNA fragmentation, determined by photometric enzyme immunoassay. Data in $\mathbf{a}-\mathbf{c}$ are from a representative experiment. Each experiment, repeated at least three times, yielded similar results 
a

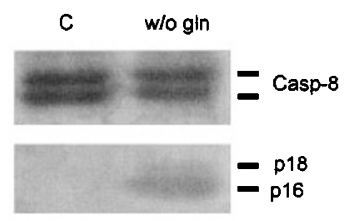

$d$

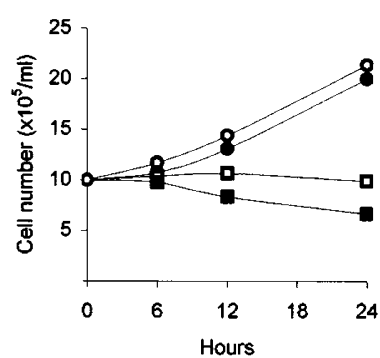

$e$

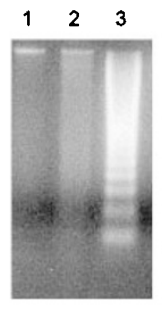

$b$

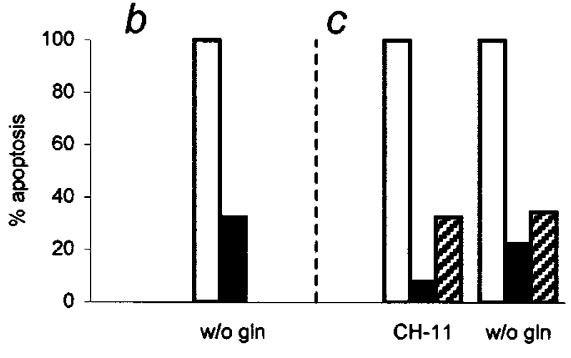

$f$

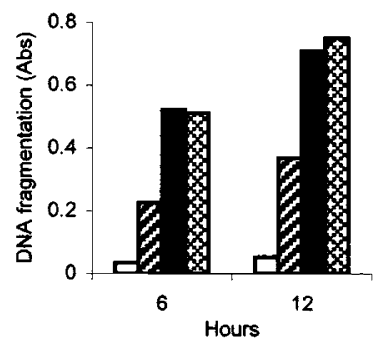

Figure 6 Expression of FADD-DN and v-Flip viral proteins (MC159, E8) inhibits the glutamine deprivation-induced activation of the CD95-dependent pathway. Cell shrinkage promoted by glutamine-deprivation is associated with a gain of agonistic function of divalent lgG anti-CD95 antibodies. (a) CEM cells were incubated for $6 \mathrm{~h}$ in the presence (C) and absence of glutamine (w/o gln) and lysate proteins were analyzed by Western blotting; the migration position of full length caspase-8 (two isoforms, Casp-8), the active subunit p18 and its further processing product p16 are indicated. (b) CEM cells were transfected with the plasmids pcDNA3,1GFP $\triangle$ FADD ( $\mathbf{a})$ or with pEGFP-C1 $(\square)$ as control (see Materials and Methods) and incubated for $16 \mathrm{~h}$ in glutamine-containing or in glutamine-free medium (w/o gln). Apoptosis was quantitated by fluorescence microscopy on GFP-positive cells stained with Hoechst 33342; data are expressed as per cent values relative to pEGFP-C1-transfected cells after correction for dead cells counted in plasmid-transfected cells incubated in control medium. (c) CEM cells were cotransfected with the plasmids: pCl-neo $(\square)$, pCl-MC159 ( $\mathbf{a})$ or pCl-E8 $(\boldsymbol{\Psi})$ along with pEGFP-C1 (see Materials and Methods) and incubated for $16 \mathrm{~h}$ in glutamine containing FCSsupplemented RPMI 1640 in the presence of $0.1 \mu \mathrm{g} / \mathrm{ml}$ of anti-CD95 antibody $(\mathrm{CH}-11)$ or in glutamine-free medium (w/o gln). Apoptosis was quantitated by fluorescence microscopy on GFP-positive cells stained with Hoechst 33342; data are expressed as per cent values relative to pCl-neo-transfected cells after correction for dead cells counted in plasmid-transfected cells incubated in control medium. (d) CEM cells, seeded at the initial density of $1 \times 10^{6}$ cells $/ \mathrm{ml}$, were incubated in glutamine-containing medium in the absence $(O)$ or in the presence of $0.5 \mu \mathrm{g} / \mathrm{ml}$ divalent IgG 2 SM1/1 anti-CD95 antibody (O) and in glutamine-free medium in the absence $(\square)$ or in the presence of the same anti-CD95 antibody ( $\mathbf{\square})$; cell survival at the indicated time intervals was assessed by Trypan blue exclusion. (e) Low molecular-mass DNA was extracted from cells incubated for $24 \mathrm{~h}$ in glutamine-containing medium in the absence (lane 1 , controls) and in the presence of $0.5 \mu \mathrm{g} / \mathrm{ml} \mathrm{lgG}_{2 a}$ SM1/1 anti-CD95 antibody (lane 2) or in glutamine-free medium (lane 3), and resolved in agarose gel electrophoresis. (f) Cells were incubated for $6-12 \mathrm{~h}$ in glutamine-containing $(\square)$ or in glutamine-free medium in the absence ( $\mathbf{C}$ ) and in the presence of $0.5 \mu \mathrm{g} / \mathrm{ml}$ IgG $\mathrm{SM} 1 / 1$ anti-CD95 antibody $(\boldsymbol{\square})$ or in glutamine-containing medium supplemented with $0.5 \mu \mathrm{g} / \mathrm{ml} \mathrm{IgM} \mathrm{CH}-11$ anti-CD95 antibody (\$); DNA fragmentation was evaluated by photometric enzyme immunoassay. Data in $\mathbf{b}-\mathbf{d}$ and $\mathbf{f}$ are from a representative experiment. Each experiment, repeated at least four times, yielded similar results

density compatible with their spontaneous (or divalent antiCD95 antibody-mediated) functional multimerization. Retained cell viability and lack of apoptosis in CD95-negative L1210 cells induced to shrink by glutamine deprivation agree with this interpretation (see Figure 5).

\section{Amidohydrolase-enzyme treatments}

Amidohydrolase enzymes purified from a variety of bacterial sources include asparaginases and glutaminases that catalyze the hydrolysis of asparagine to aspartic acid and of glutamine to glutamic acid. ${ }^{31-33,49,50}$ Conditions of glutamine deprivation associated with effects comparable to those described above (cell shrinkage, activation of the CD95 pathway followed by apoptotic cell death) were generated by supplementation of the culture medium (RPMI 1640 containing 2 mM glutamine and 10\% dialyzed FCS, $\mathrm{pH} 7.4$ ) with asparaginase (L-asparagine amidohydrolase from $E$. coli; $\mathrm{pH}$ range of activity, 5-9) at concentration of $2 \mathrm{U} / \mathrm{ml}$. This treatment lowered sharply the concentration of glutamine in the medium (Figure 7a) and, within $24 \mathrm{~h}$, caused massive apoptosis in cultured CEM (Figure 7b) and HL60 cells, but not in CD95-negative L1210 cells (not shown). At $2 \mathrm{U} / \mathrm{ml}$ glutaminase (L-glutamine amidohydrolase from E. coli, pH optimum 4.9) lowered glutamine concentration even faster than it did at $\mathrm{pH}$ values below 5.8 that were toxic for the cells. In addition to glutamine, asparaginase from $E$. coli depletes the medium of asparagine (being in fact catalytically more specific for asparagine than for glutamine). To determine whether the deprivation of asparagine had a role in the induction of the apoptotic process CEM cells were incubated in an asparagine-free RPMI 1640. As shown in Figure $7 \mathrm{c}-\mathrm{f}$ asparagine depletion was not associated with cell shrinkage, caspase activation, DNA fragmentation and did not affect cell proliferation for at least $24 \mathrm{~h}$.

\section{Discussion}

Physical perturbations of the membrane by UV light or by osmotic shock have been reported to induce clustering of cell surface receptors for growth factors and cytokines. ${ }^{51}$ Recent observations suggest that surface CD95 is pre- 
a

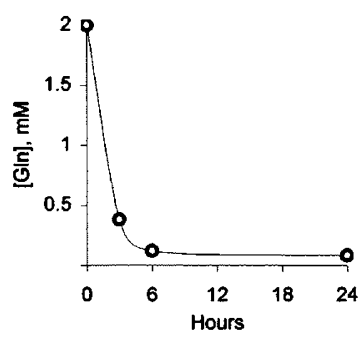

$d$

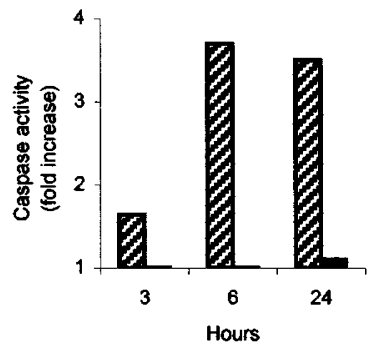

$b$

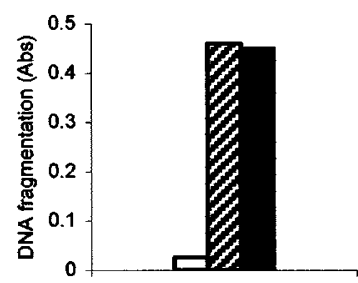

$e$

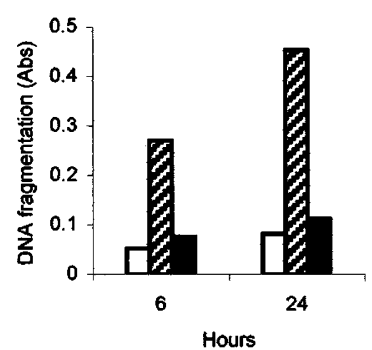

$c$

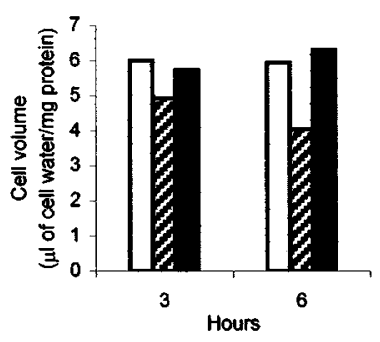

$f$

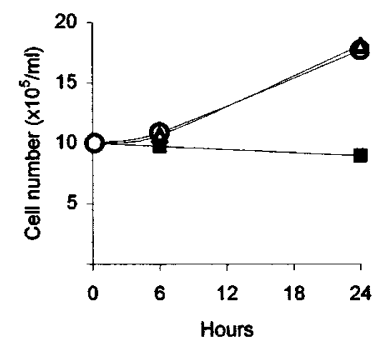

Figure 7 Asparaginase lowers glutamine concentration in cell culture medium and induces a massive CD95-mediated apoptosis in a process not affected by asparagine-depletion. (a) Changes in glutamine concentration of the culture medium (RPMI 1640 containing $2 \mathrm{mM}$ glutamine and $10 \%$ dialyzed FCS, pH 7.4 ) supplemented with $2 \mathrm{U} / \mathrm{ml}$ asparaginase (L-asparagine amidohydrolase); glutamine concentration was determined by spectrophotometric enzyme assay. (b) CEM cells were incubated for $24 \mathrm{~h}$ in glutamine containing RPMI 1640 in the absence ( $\square$ ) and in the presence of $2 \mathrm{U} / \mathrm{ml}$ asparaginase ( $\square$ ) or in glutamine-free medium ( $)$; DNA fragmentation was evaluated by photometric enzyme immunoassay. CEM cells were incubated for $3-24 \mathrm{~h}$ in reconstituted glutamine-containing (controls, $\square$ ) and glutamine-free RPMI 1640 medium ( $\boldsymbol{\Delta}$ ) or in a reconstituted glutamine-containing, asparagine-free medium ( $\boldsymbol{\square}$ ) and assayed for : (c) cell volume ( $\mu$ l of cell water/mg protein) estimated by transmembrane ${ }^{3} \mathrm{H}-\mathrm{OMG}$ distribution, (d) caspase activity, expressed as fold activation relative to control cells and (e) DNA fragmentation, determined by photometric enzyme immunoassay. (f) Viability and proliferation of CEM cells incubated in glutamine-containing ( $\bigcirc)$, glutaminecontaining, asparagine-free $(\triangle)$ and glutamine-free $(\boldsymbol{\square})$ medium were assessed by cell count using Trypan blue exclusion. Data in panels a-f are from a representative experiment. Each experiment, repeated at least three times, yielded similar results

assembled into functionally neutral trimers by self-association domains mapping to the extracellular region of the receptor $^{52,53}$ and that a high local density of death domains at the membrane (by CD95/FADD interaction) is required to send the cell death signal. ${ }^{20}$ Here we show that the CD95dependent signaling mechanism is activated by the physical perturbation associated with the glutamine deprivationinduced cell shrinkage and that this activation promotes the apoptotic death in CEM and HL-60 cells. Experiments with FADD-DN-, MC159- and E8-transfected cells suggest that the activation of the CD95-implemented pathway starts at the cell surface possibly by CD95-receptor multimerization that promotes the initial recruitment of FADD and caspase-8 required to propagate the caspase cascade. An increased propensity of oligomeric CD95 receptors to aggregate (bringing together intracellular death domains separated in the basal state) or a stabilization of interacting receptor subunits may result from the reduced tension of the cell surface that is likely to occur in cells induced to shrink and from the associated dehydration that may contribute local threshold concentrations for receptor functional activation. Consistent with this proposition are the gain-of-(agonistic)function exhibited by divalent anti-CD95 antibodies in CEM cells incubated in the absence of glutamine and the resistance to the shrinkage-induced apoptosis of CD95negative mouse L1210 cells, in which a transient expression of CD95 has been reported to confer sensitivity to killing by anti-CD95 agonistic antibodies. ${ }^{54}$
The induction of the CD95 pathway by cell shrinkage is not a CEM cell-line-specific phenomenon since it has been also observed in HL-60 cells and suggested for Jurkat ${ }^{41}$ and U937 cells. ${ }^{44}$ If this cell shrinkage-dependent process occurs in other CD95-expressing cell types, CD95 could be considered as a cell size-detecting pro-apoptotic sensor that activates a death pathway when a whatever induced persistent decrement in cell volume becomes incompatible with cell survival. Apparently, the persistence of the cell volume decrement is a necessary requirement for the activation of the apoptotic pathway, since cells displaying RVI (regulatory volume increase) that recover rapidly their initial volume were found to be resistant against apoptosis promoted by hyperosmotic stress. ${ }^{55}$ These observations underlie a cell-specific impact of shrinkage in CD95induced apoptosis, likely attributable to clustering and activation of receptors at the cell surface. The barely detectable surface expression of TNFR-1 in CEM cells clone 13 (C Fumarola and GG Guidotti, unpublished observations) and the resistance of $\mathrm{L} 1210$ cells (that express both TNFR p60 and p80 on the surface ${ }^{56}$ ) to glutamine deprivation-induced cell death suggest that TNF receptors are not primarily involved in the shrinkagedependent activation of the apoptotic pathway. However, our results do not rule out the possibility that glutamine deprivation might also promote aggregation/activation of other death domain-containing receptors known to relay apoptotic signals via FADD. ${ }^{57,58}$ Recent observations 
suggest that shrinkage might have an even deeper significance in cell death induced by a variety of apoptotic stimuli, being an early prerequisite that promotes, per se, the execution of the downstream events of apoptosis. ${ }^{44}$ If so, further mechanisms by which cell volume loss could be identified by cellular sensors and transduced into apoptotic signals must be envisaged. ${ }^{45}$

Checkpoints play a significant role in chemotherapeutic strategies to eliminate cancer cells and a variety of agents kill cancer cells by activating checkpoint-mediated apoptosis pathways. ${ }^{59}$ Asparaginase has been found to induce cell cycle arrest and apoptosis in murine lymphoma/leukemia cell lines. ${ }^{60,61}$ The contribution of the asparaginase-induced glutamine deprivation to the anti-leukemic therapy may result from a shrinkage-dependent targeting of a cell sizecontrol checkpoint with activation of a CD95-mediated death pathway. In most cases of acute lymphoblastic leukemia the cells constitutively express surface CD95 receptors, but functional studies indicated that they are rather resistant to apoptosis upon CD95-triggering by anti-CD95 antibodies. ${ }^{62}$ The asparaginase treatment, by promoting glutamine depletion that favors functional CD95 clustering, may enhance the cytotoxic activity of the associated anticancer drugs in the combined therapy of ALL and account for direct anti-tumor effects in patients with lymphoblastic leukemiabearing type-II Myc-sensitized cells (like CEM) in which CD95-induced cell death is enhanced by cytochrome $c$ release from mitochondria. ${ }^{19}$ However, amidohydrolase therapy often has severe side effects ${ }^{34}$ and, despite its relative cytotoxic selectivity toward malignant cells, disorders of clinical relevance may result from a temporary insufficient supply of glutamine in specific organs or compartments with metabolic derangements, including induction of apoptosis. ${ }^{34,63,64}$ Moreover, the decreased extracellular glutamine concentration in the central nervous system ${ }^{65}$ may seriously impair the function of the recently characterized GInT transporter $(\mathrm{Km} \cong 0.5 \mathrm{mM})$ in glutaminergic neurons ${ }^{14}$ that depends on glutamine as precursor of the neurotransmitter glutamate.

\section{Materials and Methods}

\section{Cells and culture conditions}

CEM cells clone 13 (lymphoblastic leukemia CD4+enriched cells) from our collection, ${ }^{16}$ CEM-CCRF, HL-60, and murine L1210 cell lines purchased from the American Type Culture Collection (Rockville, MD, USA) were maintained in $10 \%$ FCS-supplemented RPMI 1640 at $37^{\circ} \mathrm{C}$ in an atmosphere of $5 \% \mathrm{CO}_{2}$ in air. Cultures were split $24 \mathrm{~h}$ before the experiments. ${ }^{16}$ All measurements were made on subcultures (0.5$1 \times 10^{6}$ cells $/ \mathrm{ml}$ ) seeded into $25 \mathrm{~cm}^{2}$ flasks and incubated for $0.5-$ $24 \mathrm{~h}$ in $2 \mathrm{mM}$ glutamine-containing or glutamine-free RPMI 1640 (or reconstituted RPMI, see Results) supplemented with $10 \%$ dialyzed FCS. When used, caspase inhibitors were added to the medium at the beginning of cell incubation.

\section{Antibodies, enzymes and reagents}

Monoclonal anti-CD95 IgM antibody $\mathrm{CH}-11$ and mouse FITCconjugated IgG isotype were obtained from Immunotech, Coulter Co.
(Miami, FL, USA). Monoclonal anti-CD95 IgG antibodies SM1/1, APO1-3, SM1/23 and FITC-conjugated SM1/23 were purchased from Bender MedSystems (Vienna, Austria). Monoclonal mouse antiCD95L antibody NOK-1 was provided by PharMingen (San Diego, CA, USA). Polyclonal rabbit anti-CD95L antibody $\mathrm{N}-20$, polyclonal goat anti-caspase-8 antibody p20 and HRP-conjugated donkey antigoat secondary antibody were from Santa Cruz Biotechnology Inc. (Santa Cruz, CA, USA). Monoclonal mouse anti-CD95L antibody clone 33, HRP-conjugated goat anti-rabbit and HRP-conjugated goat antimouse secondary antibodies were from Transduction Laboratories (Lexington, KY, USA). Sheep anti-mouse Ig-fluorescein $F\left(a b^{\prime}\right)_{2}$ fragment was provided by Roche (Mannheim, Germany). Caspase inhibitors z-IETD-FMK and z-DEVD-FMK were purchased from Enzyme Systems Products (Livermore, CA, USA). Metalloproteinase inhibitor KB8301 was obtained from PharMingen. 3-o-methyl-D$\left[1-{ }^{3} \mathrm{H}\right]$ glucose $(4.5 \mathrm{Ci} / \mathrm{mmol})$ was purchased from Amersham Pharmacia Biotech (Buckinghamshire, UK). L-Asparagine amidohydrolase, Lglutamine amidohydrolase, glutamine/glutamate determination kit and all other reagents were from Sigma-Aldrich (St. Louis, MO, USA).

\section{Detection of apoptosis}

Apoptosis was assessed by: (a) morphology on stained (Hoechst 33342, propidium iodide) or unstained cells using light-, phasecontrast- and fluorescence-microscopy; (b) FITC-conjugated Annexin $\mathrm{V}$ assay (Bender MedSystems); (c) DNA fragmentation by gel electrophoresis analysis (DNA extracted with phenol-chloroform, resolved in $1.4 \%$ agarose gel and stained with ethidium bromide) and by photometric enzyme immunoassay (Cell Death Detection ElisaPLUS, Roche); (d) caspase-8 and caspase-3 activity (Caspase Colorimetric Assay Kit, MBL Intern. Corp., Watertown, MA, USA) and inhibition by specific tetrapeptides (z-IETD-FMK for caspase-8 and zDEVD-FMK for caspase-3); (e) caspase-8 activation (detection of cleavage products in Western blotting): $50 \mu \mathrm{g}$ protein from CEM cell lysates were resolved by SDS-PAGE and transferred to nitrocellulose membranes; immunodetection was done using an enhanced chemiluminescence system (primary anti-caspase-8 antibody, 1:200 dilution, and HRP-conjugated secondary antibody, $1: 2000$ dilution).

\section{CD95 ligand/CD95 expression and activity}

Total expression of CD95 receptor in CEM cells was quantitated by a Fas/Apo-1 ELISA Kit according to the manufacturer's instructions (Calbiochem, La Jolla, CA, USA). CD95 expression on the cell surface was assayed by flow cytometry (Coulter EPICS XL-MCL, Miami, Florida, USA) using the monoclonal mouse FITC-conjugated SM1/23 anti-CD95 antibody and a mouse FITC-conjugated IgG as isotypic control. Total expression of CD95L was estimated by Western blotting. CEM cells were lysed and $50 \mu \mathrm{g}$ protein from lysates were resolved by SDS-PAGE and transferred to nitrocellulose membranes. Immunodetection was done using an enhanced chemiluminescence system (primary anti-CD95L antibodies, 1:1000 dilution, and HRP-conjugated secondary antibodies, 1:5000 dilution). Surface expression of CD95L was assayed by flow cytometry (Coulter EPICS XL-MCL). Cells were treated with $10 \mu \mathrm{M} \mathrm{KB8301} \mathrm{(metalloproteinase} \mathrm{inhibitor)} \mathrm{added} \mathrm{to} \mathrm{the}$ medium during the incubation and stained with the monoclonal mouse anti-CD95L NOK-1 primary antibody $(10 \mu \mathrm{g} / \mathrm{ml})$ followed by a sheep anti-mouse Ig-fluorescein $\mathrm{F}\left(\mathrm{ab}^{\prime}\right)_{2}$ fragment (1:100 dilution). In these experiments a PHA-stimulated T-cell clone, triggered for 5 and $10 \mathrm{~min}$ with ionomycin after addition of NOK-1 (a treatment that promotes the delivery of CD95L to the cell surface), ${ }^{66}$ was used as a positive control. CD95L functional apoptotic activity was evaluated in CEM 
cells incubated: (a) in glutamine-free RPMI supplemented with $10 \mu \mathrm{g} /$ $\mathrm{ml}$ of the neutralizing anti-CD95L NOK-1 antibody or with the antiCD95 SM1/23 antibody at a concentration $(10 \mu \mathrm{g} / \mathrm{ml})$ that suppressed completely the CD95-mediated apoptosis induced by a $0.5 \mu \mathrm{g} / \mathrm{ml}$ of the agonistic anti-CD95 IgM antibody $\mathrm{CH}-11$ (in these experiments cells were always preincubated for $60 \mathrm{~min}$ in complete RPMI containing the neutralizing antibodies) and (b) in glutamine-containing and in glutamine-free RPMI in the presence of $10 \mu \mathrm{M} \mathrm{KB} 8301$ (metalloproteinase inhibitor). The concentration of soluble CD95L in the culture medium of CEM cells incubated in the presence and absence of glutamine was estimated by an ELISA kit provided by MBL Intern. Corp.

\section{Cell volume}

Cellular volumes were estimated by measurements of cell water based on the steady-state transmembrane distribution of 3-o-methyl-D$\left[1-{ }^{3} \mathrm{H}\right.$ ]glucose (OMG) as described previously. ${ }^{12}$ Labeled OMG was added during the last 30-40 min of incubation to control or modified mediums (see Results) whose glucose concentration had been reduced to $0.5 \mathrm{mM}$. The cells were then quickly washed twice in icecold PBS containing $0.1 \mathrm{mM}$ phloretin and extracted in ice-cold $10 \%$ trichloroacetic acid. Radioactivity was measured by liquid-scintillation counting in three independent determinations. The protein content of the pellets was measured by Bradford assay (Bio-Rad Laboratories, Hercules, CA, USA). Previous experiments had shown that, under the conditions adopted, the tracer reached in/out equilibrium in less than $30 \mathrm{~min}$ and that its outward flow during the cell washing procedure in cold PBS was negligible and unaffected by the preceding conditions of incubation. Data are expressed as $\mu \mathrm{l}$ of cell water $/ \mathrm{mg}$ protein. Geometry parameters (area, diameter) of the cells cultured in the presence or in the absence of glutamine were assessed directly during the incubation (at $37^{\circ} \mathrm{C}$ in air- $5 \% \mathrm{CO}_{2}$ ) by computer-assisted image analysis (image-pro Plus Media Cybernetics, Silver Spring, MA, USA). The software provided measurements of area and diameter (max., min., ave.) for each cell in the population explored. At least 500 cells between 6 and $20 \mu \mathrm{m}$ in diameter were recorded for each experimental condition.

\section{Plasmids and transfection procedures}

pCl-neo was purchased from Promega (Madison, WI, USA). pEGFPC1 was obtained from Clontech Laboratories (Palo Alto, CA, USA). pCl-MC159 and pCl-E8 were kindly provided by Dr. Jeffrey Cohen (NIH, Bethesda, MD, USA). pcDNA3,1-GFP $\triangle$ FADD was a generous gift of Drs. Harald Wajant and Frank Muehlenbeck (University of Stuttgart, Germany). CEM cells were transfected by a standard electroporation procedure. In brief, $5 \times 10^{6}$ cells in FCS-free RPMI 1640 were electroporated by a pulse of $250 \mathrm{~V}, 960 \mu \mathrm{F}$ (Gene Pulser, Bio-Rad) with: (a) $15 \mu \mathrm{g}$ of pcDNA3,1-GFP $\triangle$ FADD or pEGFP-C1 as control, (b) pCl-neo, pCl-MC159 or pCl-E8 along with pEGFP-C1 at a $3: 1$ ratio $(20 \mu \mathrm{g}$ DNA total), and incubated for $24 \mathrm{~h}$ in FCSsupplemented RPMI 1640. Dead cells resulting from the transfection procedures were eliminated by magnetic cell sorting (Dead Cell Removal Kit, Miltenyi Biotech, Bergisch Gladbach, Germany). Viable cells were then incubated for $16 \mathrm{~h}$ in glutamine-containing or in glutamine-free FCS-supplemented RPMI 1640 medium. As controls, transfected cells were incubated in complete RPMI medium supplemented with $0.1 \mu \mathrm{g} / \mathrm{ml}$ of anti-CD95 IgM agonistic antibody (CH-11). Apoptosis was quantitated by fluorescence microscopy on GFP-positive cells stained with Hoechst 33342 dye. Cells were scored positive if they had a pyknotic and/or fragmented nucleus.
Representative graphs are shown for experiments where at least 200 cells were scored.

\section{Acknowledgements}

This work was supported by Ministero dell'Università e della Ricerca Scientifica e Tecnologica, (Murst 1999), Roma, Italy.

\section{References}

1. Kovacevic $Z$ and Morris HP (1972) The role of glutamine in the oxidative metabolism of malignant cells. Cancer Res. 32: 326-333

2. Windmueller HG and Spaeth $A E$ (1974) Uptake and metabolism of plasma glutamine by the small intestine. J. Biol. Chem. 249: 5070-5079

3. Reitzer LJ, Wice BM and Kennell D (1979) Evidence that glutamine, not sugar, is the major energy source for cultured HeLa cells. J. Biol. Chem. 254:2669-2676

4. Zielke HR, Zielke CL and Ozand PT (1984) Glutamine: a major energy source for cultured mammalian cells. Fed. Proc. 43: $121-125$

5. Ardawi MSM (1988) Glutamine and glucose metabolism in human peripheral lymphocytes. Metabolism 37: 99-103

6. Brand K (1985) Glutamine and glucose metabolism during thymocyte proliferation. Biochem. J. 228: 353-361

7. Szondy $Z$ and Newsholme EA (1989) The effect of glutamine concentration on the activity of carbamoyl-phosphate synthase II and on the incorporation of $\left[{ }^{3} \mathrm{H}\right]$ thymidine into DNA in rat mesenteric lymphocytes stimulated by phytohaemagglutinin. Biochem. J. 261:979-983

8. Hörig H, Spagnoli GC, Filgueira L, Babst R, Gallati H, Harder F, Juretic A and Heberer M (1993) Exogenous glutamine requirement is confined to late events of T cell activation. J. Cell. Biochem. 53: 343-351

9. CalderPC and YaqoobP (1999) Glutamine and the immune system. Amino Acids 17: $227-241$

10. Kitoh T, Kubota M, Takimoto T, Hashimoto H, Shimizu T, Sano H, Akiyama Y and Mikawa $H$ (1990) Metabolic basis for differential glutamine requirements of human leukemia cell lines. J. Cell. Physiol. 143: 150-153

11. Colquhoun A and Newsholme EA (1997) Aspects of glutamine metabolism in human tumour cells. Biochem. Mol. Biol. Int. 41: 583-596

12. Gazzola GC, Dall'Asta V, Nucci FA, Rossi PA, Bussolati O, Hoffmann EK and Guidotti GG (1991) Role of amino acid transport system A in the control of cell volume in cultured human fibroblasts. Cell. Physiol. Biochem. 1: 131-142

13. Dall'Asta V, Rossi PA, Bussolati O and Gazzola GC (1994) Response of human fibroblasts to hypertonic stress. Cell shrinkage is counteracted by an enhanced active transport of neutral amino acids. J. Biol. Chem. 269: 10485-10491

14. Varoqui $\mathrm{H}$, Zhu H, Yao D, Ming $\mathrm{H}$ and Erickson JD (2000) Cloning and functional identification of a neuronal glutamine transporter. J. Biol. Chem. 275: 40494054

15. Guidotti GG, Alfieri R, Urbani S, Petronini PG and Borghetti AF (1994) Engagement in apoptosis of lymphoma-leukaemia cell lines by glutamine deprivation. FASEB J. 8: A807

16. Petronini PG, Urbani S, Alfieri R, Borghetti AF and Guidotti GG (1996) Cell susceptibility to apoptosis by glutamine deprivation and rescue: Survival and apoptotic death in cultured lymphoma-leukemia cell lines. J. Cell. Physiol. 169: $175-185$

17. Urbani S, Fumarola C, Ponderato N, Alfieri R, Petronini PG, Borghetti AF and Guidotti GG (1996) c-Myc has a role in glutamine deprivation-induced apoptosis of CEM cells. Fundam. Clin. Immunol. 4: 27-30

18. Hueber AO, Zörnig M, Lyon D, Suda T, Nagata S and Evan G(1997)Requirement for the CD95 receptor-ligand pathway in c-Myc-induced apoptosis. Science 278: $1305-1309$

19. Juin P, Hueber AO, Littlewood T and Evan G (1999) c-Myc-induced sensitization to apoptosis is mediated through cytochrome c release. Gene Dev. 13: 13671381

20. Golstein P (2000) FasL binds preassembled Fas. Science 288: 2328-2329

21. Krammer PH (2000) CD95's deadly mission in the immune system. Nature 407: $789-795$ 
22. Kischkel FC, Hellbardt S, Behrmann I, Germer M, Pawlita M, Krammer PH and Peter ME (1995) Cytotoxicity-dependent APO-1 (Fas/CD95)-associated proteins form a death-inducing signaling complex (DISC) with the receptor. EMBO J. 14: $5579-5588$

23. Scaffidi C, Fulda S, Srinivansan A, Friesen C, Li F, Tomaselli KJ, Debatin KM, Krammer PH and Peter ME (1998) Two CD95 (Apo-1/Fas) signaling pathways. EMBO J. 17: 1675-1687

24. Luo X, Budihardjo I, ZouH, Slaughter C and Wang X (1998)Bid, a Bcl2 interacting protein, mediates cytochrome $c$ release from mitochondria in response to activation of cell surface death receptors. Cell 94: 481-490

25. Li H, Zhu H, Xu C and Yuan J (1998) Cleavage of BID by caspase- 8 mediates the mitochondrial damage in the Fas pathway of apoptosis. Cell 94: 491-501

26. Rehemtulla A, Hamilton CA, Chinnaiyan AM and Dixit VM (1997) Ultraviolet radiation-induced apoptosis is mediated by activation of CD-95 (Fas/Apo-1). J. Biol. Chem. 272: 25783-25786

27. Aragane Y, Kulms D, Metze D, Wilkes G, Poppelmann B, Luger TA and Schwarz T (1998) Ultraviolet light induces apoptosis via direct activation of CD95 (Fas/ Apo-1) independently of its ligand CD95L. J. Cell. Biol. 140: 171-182

28. Faubion WA, Guicciardi ME, Miyoshi H, Bronk SF, Roberts PJ, Svingen PA, Kaufmann SH and Gores GH (1999) Toxic bile salts induce rodent hepatocyte apoptosis via direct activation of Fas. J. Clin. Invest. 103: 137-145

29. Micheau O, Solary E, Hammann A and Dimanche-Boitrel MT (1999) Fas ligandindependent, FADD-mediated activation of the Fas death pathway by anticancer drugs. J. Biol. Chem. 274: 7987-7992

30. Sheikh MS, Antinore MJ, Huang Y and Fornace AJ Jr (1998) Ultravioletirradiation-induced apoptosis is mediated via ligand independent activation of tumor necrosis factor receptor 1. Oncogene 17: 2555-2563

31. Roberts J, Holcenberg JS and Dolowy WC (1992) Isolation, crystallization, and properties of Achromobacteraceae glutaminase-asparaginase with antitumor activity. J. Biol. Chem. 247: 84-90

32. Roberts J (1976) Purification and properties of a highly potent antitumor glutaminase-asparaginase from Pseudomonas 7A. J. Biol. Chem. 251:21192123

33. Boos J, Werber G, Ahlke E, Schulze-Westhoff P, Nowak-Göttl U, Würthwein G, Verspohl EJ, Ritter J and Jürgens H (1996) Monitoring of asparaginase activity and asparagine levels in children on different asparaginase preparations. Eur. J. Cancer 32A: $1544-1550$

34. Muller HJ and Boos J (1998) Use of L-asparaginase in childhood ALL. Crit. Rev. Oncol. Hematol. 28: 97-113

35. AmylonMD, ShusterJ, PullenJ,BerardC, LinkMP, WharamM, KatzJ, YuA, Laver J,RavindranathY,KurtzbergJ,DesaiS,CamittaBandMurphySB(1999)Intensive high-dose asparaginase consolidation improves survival for pediatric patients with $\mathrm{T}$ cell acute lymphoblastic leukemia and advanced stage lymphoblastic lymphoma: a Pediatric Oncology Group study. Leukemia 13: 335-342

36. Spiers ASD and Wade HE (1976) Bacterial glutaminase in treatment of acute leukemia. Br. Med. J. 1: 1317-1319

37. Ollenschläger G, Roth E, Linkesch W, Jansen S, Simmel A and Mödder B (1988) Asparaginase-induced derangements of glutamine metabolism: the pathogenetic basis for some drug-related side-effects. Eur. J. Clin. Invest. 18: 512-516

38. Kitoh T, Asai S, Akiyama Y, Kubota M and Mikawa H (1992) The inhibition of lymphocyte blastogenesis by asparaginase: critical role of glutamine in both $\mathrm{T}$ and B lymphocye transformation. Acta Pediatr. Jpn. 34: 579-583

39. Mariani SM, Matiba B, Baumler C and Krammer PH (1995) Regulation of cell surface Apo-1/Fas (CD95) ligand expression by metalloproteases. Eur. J. Immunol. 25: 2303-2307

40. Law RO and Turner DPJ (1987) Are ninhydrin-positive substances volumeregulatory osmolytes in rat renal papillary cells? J. Physiol. 386: 45-61

41. Gómez-Angelats M, Bortner CD and CidlowskiJA (2000) Protein kinase C (PKC) inhibits Fas receptor-induced apoptosis through modulation of the loss of $\mathrm{K}^{+}$and cell shrinkage. J. Biol. Chem. 275: 19609-19619

42. Guidotti GG and Gazzola GC (1992) Amino acid transporters: Systematic approach and principles of control. In Mammalian Amino Acid Transport Mechanisms and Control, Kilberg MS and Häussinger D, eds (New York: Plenum Press) pp. 3-29

43. Szabo I, Lepple-Weinhues A, Kaba KN, Zoratti M, Gulbins E and Lang F (1998) Thyrosine kinase-dependent activation of a chloride channel in CD95-induced apoptosis in T lymphocytes. Proc. Natl. Acad. Sci. USA 95: 6169-6174

44. Maeno E, Ishizaki Y, Kanaseki T, Hazama A and Okada Y (2000) Normotonic cell shrinkage because of disordered volume regulation is an early prerequisite to apoptosis. Proc. Natl. Acad. Sci. USA 97: 9487-9492
45. Ping Yu Sand Choi DW (2000) lons, cell volume, and apoptosis. Proc. Natl. Acad. Sci. USA 97: $9360-9362$

46. Wajant H, Johannes FJ, Haas E, SiemienskiK, Schwenzer R, Schubert G, Weiss T, Grell M and Scheurich P (1998) Dominant-negative FADD inhibits TNFR60-, Fas/Apo1- and TRAIL-R/Apo2-mediated cell death but not gene induction. Curr. Biol. 8: 113-116

47. Hu S, Vincenz C, Buller M and Dixit VM (1997) A novel family of viral death effector domain-containing molecules that inhibit both CD-95- and tumor necrosis factor receptor-1-induced apoptosis. J. Biol. Chem. 272: 9621-9624

48. Bertin J, Armstrong RC, Ottilie S, Martin DA, Wang Y, Banks S, Wang GH, Senkevich TG, Alnemri ES, Moss B, Lenardo MJ, Tomaselli KJ and Cohen JI (1997) Death effector domain-containing herpesvirus and poxvirus proteins inhibit both Fas and TNFR-1-induced apoptosis. Proc. Natl. Acad. Sci. USA 94: 1172-1176

49. Mashburn LT and Wriston JC Jr (1964) Tumor inhibition effect of L-asparaginase from Escherichia Coli. Arch. Biochem. Biophys. 105: 450-452

50. Wade HE, Elsworth R, Herbert D, Keppie J and Sargeant K (1968) A new Lasparaginase with antitumour activity? Lancet 2: 776-777

51. Rosette C and Karin M (1996) Ultraviolet light and osmotic stress: activation of the JNK cascade through multiple growth factor and cytokine receptors. Science 274: $1194-1197$

52. Papoff G, Hausler P, Eramo A, Pagano MG, Di Leve G, Signore A and Ruberti G (1999) Identification and characterization of a ligand-independent oligomerization domain in the extracellular region of the CD95 death receptor. J. Biol. Chem. 274: $38241-38250$

53. Siegel RM, Frederiksen JK, Zacharias DA, Ka-Ming Chan F, Johnson M, Lynch D, Tsien RY and Lenardo MJ (2000) Fas preassociation required for apoptosis signaling and dominant inhibition by pathogenic mutations. Science 288: $2354-$ 2357

54. Memon SA, Hou J, Moreno MB and Zacharchuk CM (1998) Cutting edge: apoptosis induced by a chimeric Fas/FLICE receptor: lack of requirement for Fas- or FADD-binding proteins. J. Immunol. 160: 2046-2049

55. Bortner CD and Cidlowski JA (1996) Absence of volume regulatory mechanisms contributes to the rapid activation of apoptosis in thymocytes. Am. J. Physiol. 271: C950-C961

56. Tsukada N, Kobata T, Aizawa Y, Yagita H and Okumura K (1999) Graft-versusleukemia effect and graft-versus-host disease can be differentiated by cytotoxic mechanisms in a murine model of allogeneic bone marrow transplantation. Blood 93: $2738-2747$

57. Marsters SA, Sheridan JP, Pitti RM, Brush J, Goddard A and Ashkenazi A (1998) Identification of a ligand for the death-domain-containing receptor Apo3. Curr Biol. 8: 525-528

58. Kischkel FC, Lawrence DA, Chuntharapai A, Schow P, Kim KJ and Ashkenazi A (2000) Apo2L/TRAIL-dependent recruitment of endogenous FADD and caspase-8 to death receptors 4 and 5. Immunity 12: 611-620

59. Elledge SJ (1996) Cell cycle checkpoints: preventing an identity crisis. Science 274: $1664-1672$

60. Story MD, Voehringer DW, Stephens LC and Meyn RE (1993) L-asparaginase kills lymphoma cells by apoptosis. Cancer Chemother. Pharmacol. 32: 129-133

61. Ueno T, Ohtawa K, Mitsui K, Kodera Y, Hiroto M, Matsushima A, Inada Y and Nishimura $H$ (1997) Cell cycle arrest and apoptosis of leukemia cells induced by L-asparaginase. Leukemia 11: $1858-1861$

62. Karawajew L, Wuchter C, Ruppert V, Drexler H, Gruss HJ, Dorken B and Ludwig WD (1997) Differential CD95 expression and function in T and B lineage acute lymphoblastic leukemia cells. Leukemia 11: 1245-1252

63. Papaconstantinou HT, Hwang KO, Rajaraman S, Hellmich MR, Townsend CM Jr and Ko TC (1998) Glutamine deprivation induces apoptosis in intestinal epithelial cells. Surgery 124: $152-160$

64. Bushman JE, Palmieri D, Whinna HC and Church FC (2000) Insight into the mechanism of asparaginase-induced depletion of antithrombin III in treatment of childhood acute lymphoblastic leukemia. Leuk. Res. 24: 559-565

65. Korinthenberg R, Ullrich K, Ritter J and Stephani U (1990) Electrolytes, amino acids and proteins in lumbar CSF during the treatment of acute leukemia in childhood. Acta Paediatr. Scand. 79: 335-342

66. Bossi G and Griffiths GM (1999) Degranulation plays an essential part in regulating cell surface expression of Fas ligand in T cells and natural killer cells. Nature Med. 5: $90-96$ 